\title{
Influence of Bacterial Inoculation on Photosynthetic Capacity, Mineral Uptake, Total Protein and Amino Acid Content of Maize (Zea mays) under Diesel Stress
}

\author{
Ume Ummara $^{1}$, Sibgha Noreen ${ }^{1 *}$, Zafarullah Zafar ${ }^{1}$ and Muhammad Afzal ${ }^{2}$ \\ ${ }^{1}$ Institute of Pure and Applied Biology, Bahauddin Zakariya University, Multan, Pakistan \\ ${ }^{2}$ National Institute of Biotechnology and Genetic Engineering (NIBGE), Faisalabad, Pakistan \\ *Corresponding author: sibgha_noreen@yahoo.com \\ Received 02 March 2020; Accepted 20 October 2020; Published 10 January 2021
}

\begin{abstract}
This study was undertaken to explore the influence of diesel contaminated soil and bacterial consortium on photosynthetic efficiency, ion uptake, chlorophyll fluorescence, chlorophyll pigments, amino acids and total protein content of maize crop. The experiment was consisted of (a) two maize varieties (MMR1 yellow and Pearl white), (b) diesel levels (0, 1.5, 2.5, 3.5 g $\mathrm{kg}^{-1}$ soil) and (c) two bacterial strains inoculation levels, (non-inoculated) and inoculated with Pseudomonas aeruginosa BRRI54, Acinetobacter sp. ACRH80 and Acinetobacter sp. BRSI56 with completely randomized design having four replication The results exhibited that diesel contaminated soil decreased photosynthetic efficiency, photosynthetic pigments ie., 'a', 'b, carotenoids, chlorophyll fluorescence and $\mathrm{k}^{+}$content, however, there is increase in amino acid accumulation, total protein and $\mathrm{Na}^{+}$uptake. But inoculation of different bacterial strains enhanced the photosynthetic capacity of PSII, quantum yield $(\mathrm{Fv} / \mathrm{Fm}), \mathrm{K}^{+}$uptake as compared to non-inoculated group along with hydrocarbon stress. The marginal lands contaminated with diesel oil could be ameliorated with inoculation of bacterial strains, which are highly adapted to various farming systems. The maize crop could be successively grown on polluted soil which are contaminated with poly aromatic hydrocarbons. The small holding farming families will be greatly benefited to improve their crop yields. (C) 2021 Friends Science Publishers
\end{abstract}

Keywords: Pseudomonas aeruginosa BRRI54; Acinetobacter sp. ACRH80; Acinetobacter sp. BRSI56; Zea mays L.; Diesel stress; Photosynthetic capacity; Ion uptake

\section{Introduction}

The soil pollution has been considered as the "hidden danger "and a major threat to agricultural land and ecosystem across the continents (Rodríguez-Eugenio et al. 2018). The soil pollution is caused by petroleum derived products, industrial byproducts, livestock agrochemicals and municipal waste (Cachada et al. 2018). It does not degrade soil but also reduces crop yields as well as the production of products which is unsafe for consumption by humans and livestock. These pollutants cause significant harm to soil microflora, soil biodiversity and destroying the beneficial microbial population (Hentati et al. 2013; Mair et al. 2013; Baldan et al. 2015; Ramadass et al. 2015). The various plant species have differential tolerance levels to these organic pollutants (Aisien et al. 2009), because physiological processes of plants including photosynthetic efficiency, nutrients uptake and water relations (Iwegbue et al. 2007; Ibemesim 2010; Ambreen et al. 2016), photosystem II (PSII) (Li et al. 2010; Wang et al. 2012; Agnello et al.
2016) and chlorophyll contents (Li et al. 2008; Njoku et al. 2009) are the ones which are the worst affected in response to hydrocarbon contaminated soil.

The anthropogenic and mechanical error is responsible for the pollution of terrestrial land with petroleum hydrocarbons. The petroleum products spreading into different parts of the environment including soil and water due to accidental spillage worldwide, however, the exact data of petroleum hydrocarbons pollution is a hard task to present due to unintentional contamination. In Pakistan, in July 2003 a Greek ship (Tasman Spirit) cracked and resulting in 28,000 tons of crude oil accidentally polluted Karachi coastal line area. In September 2009 one more incident of an accidental spill of 18 crude oil tankers occurred in Sindh, Pakistan as a result of crashing two freight trains (Khan 2009). Another incident in Korangi Town Karachi, Pakistan was that the residental of the area found oil in their houses, streets, and shops because of destruction in the pipeline of Pak Arab Refinery Corporation (PARCO) while working of underground

To cite this paper: Ummara U, S Noreen, Z Zafar, M Afzal (2021). Influence of bacterial inoculation on photosynthetic capacity, mineral uptake, total protein and amino acid content of maize (Zea mays) under diesel stress Intl J Agric Biol 25:530-538 
construction by Sui Southern Gas Company (Alam 2008). The big oil spillage incident of two NATO oil tankers having 60,000 liters of gasoline collapsed on Khojak Pass near Chaman, Pakistan. Moreover, petroleum hydrocarbon contamination happened during the extraction of crude oil at well places, and petroleum refinery industries. The industries of petroleum refining in Pakistan are situated in Multan, Kot Adu, Qasaba Gujrat, Rawalpindi, and Karachi are the origin of contamination of oily residues sulphides, phenols, and hydrocarbons (NEPP 1999).

The extremely intricate and lethal petroleum hydrocarbons contaminate the surroundings though, complicates elimination. The conventional method (excavation, incineration, supercritical fluid oxidation and encapsulation, thermal desorption) are used for the cleanup of polluted sites (Peng et al. 2009; Khan et al. 2014) whereas these pollutants are necessary for immediate elimination and to constrain oil dispersal (Dixit et al. 2016). However, these methods exhibited demerits including high cost because of fuel consumption and less ecofriendly to environment and people (Kaimi et al. 2006). The eradication of petroleum hydrocarbons from the environs is done by an effective approach of phytoremediation (Pilon-Smits 2005; Afzal et al. 2012) Bioaugmentation is a promising strategy that remediates or detoxifies petroleum hydrocarbons with particular enzymatic characteristics by stimulating hydrocarbons microbial decontamination (Yousaf et al. 2010; Afzal et al. 2013; Sessitsch et al. 2013; Afzal et al. 2014; Souza et al. 2014; Hou et al. 2015; Xun et al. 2015; Fatima et al. 2016; Shahzad et al. 2016; Zhang et al. 2016; Ummara et al. 2020). Consequently, Plant and microbe are used together for detoxification of recalcitrant hydrocarbon pollutants (Jabeen et al. 2016; Guo et al. 2017).

Bacterial inoculation of Streptomyces sp. (Palaniyandi et al. 2014) in tomato and Burkholderia phytofirmans (Naveed et al. 2014) in maize alleviated the stress condition and subsequently enhanced biomass production. Under stress condition, in Brassica juncea inoculation (Trichoderma harzianum) mitigated $\mathrm{Na}^{+}$uptake whereas progressed nutrient up take, acquisition of antioxidant and osmolytes (Ahmad et al. 2015). The ACC deaminase activity and production of indole acetic acid (IAA) were ameliorated by inoculation of Pseudomonas sp. and Acinetobacter sp. in barley and oats under stress condition (Chang et al. 2014). Plant growth regulator directly enhanced by microbes including nitrogen fixation, $\mathrm{Fe}$ and $\mathrm{Zn}$ sequestration, $\mathrm{K}$ and $\mathrm{P}$ solubilization, phytohormone and siderophore production (Almaghrabi et al. 2013; Meena et al. 2017).

There are evidences that various bacterial strains could be utilized to degrade PAHs. Therefore, the research studies were undertaken to quantify the efficiency of the isolated bacterial strains to degrade the hydrocarbons and to determine their effects on maize crop. A vast polluted waste land is lying around high ways which could be utilized to grow cereal crops after degrading with bacterial strains. This research provides valuable understanding concerning physiological and biochemical effects of diesel contaminated soil and bacterial consortium on maize crop which could be used to subsistence the bioremediation strategy.

\section{Materials and Methods}

\section{Experimental design}

The pot-culture experimental studies were undertaken at the Institute of Pure and Applied Biology, Bahauddin Zakariya University, Multan-Pakistan. For two maize crop seasons (October-November 2017 and March-April 2018). The treatments were consisted of two maize varieties (MMRI Yellow and Pearl- white) (b), four regimes of diesel $(0.0,1.5,2.5,3.5 \mathrm{~g} / \mathrm{kg}$ soil) and (c) two bacterial strains inoculation levels, (non-inoculated) and inoculated with Pseudomonas aeruginosa BRRI54, Acinetobacter sp. ACRH80 and Acinetobacter sp. BRSI56. The treatments were arranged in a three factor factorial with completely randomized design and each treatment was repeated four times. The strains $P$. aeruginosa BRR154 and Acinetobacter BRSI56 were isolated from the root and shoot of Brachiaria mutica, respectively, whereas Acinetobacter sp. strain ACRH80 was isolated from the rhizosphere of Acacia ampliceps (Fatima et al. 2015). These bacteria were capable to degrade a range of hydrocarbons having alkane hydroxylase gene (such as alkB) and exhibiting plant growth-promoting characteristics (phosphate solubilization, siderophore production, and 1-aminocyclopropane-1carboxylate (ACC) deaminase activity) were previously characterized and reported by Fatima et al. (2015).

\section{Seed inoculation}

Bacterial strains were grown in $\mathrm{LB}$ broth at $30^{\circ} \mathrm{C}$ on a shaker $(100 \mathrm{rpm})$. The LB broth medium used for the culture of bacterial strains was harvest by centrifugation at $10,000 \mathrm{rpm}$ for $10 \mathrm{~min}$. Further washed and resuspended in sterilized normal saline solution $(0.9 \% \mathrm{NaCl}$, w/v). Then seed and soil inoculation were done by using bacterial suspension (Afzal et al. 2012; Ummara et al. 2020). Before sowing, the seeds were surface-sterilized in a $5 \%(\mathrm{v} / \mathrm{v})$ $\mathrm{NaOCl}$ for $10 \mathrm{~min}$, washed three times with sterilized distilled water. After sterilizing, the seeds were dipped in the prepared bacterial inoculum $\left(108 \mathrm{cfu} \mathrm{mL}^{-1}\right)$ for $2 \mathrm{~h}$ and numeration of bacterial inoculants in the rhizosphere soil, shoot and root samples collected at the time of harvest was checked and reported in latest study (Ummara et al. 2020). The pots were arranged in a green house in a completely randomized block designed. The plastic pots were filled with $6 \mathrm{~kg}$ of soil and contaminated with various levels of commercial disease. Five plants were maintained in each pot by thinning at 7 days after germination. 


\section{Estimation of chlorophyll (Chl) content and chlorophyll (Chl) fluorescence}

The estimation of Chl a, b, total Chl, carotenoids were carried out as previously described with certain modifications (Aronoff 1946). Briefly, $0.2 \mathrm{~g}$ of the fresh leaf was grinded in $80 \%$ acetone and absorbance was read at $663 \mathrm{~nm}, 645 \mathrm{~nm}$, and $470 \mathrm{~nm}$. Photosynthetic efficiency parameters (Y(II), Fv/Fm, NPQ) were determined using a Dual-PAM 100 (Heinz Walz, Effeltrich, Germany) subsequently maize was adapted to the dark for $30 \mathrm{~min}$, where YII (PSII quantum yield effectiveness), Fv/Fm (maximum quantum yield of PSII after dark adaptation), NPQ (PSII photo-inactivation and constitutive heat dissipation).

\section{Estimation of total soluble proteins and total free amino acid (TPS and TAA)}

TPS was quantified by using bovine serum albumin (BSA) as a standard procedure with some modification (Bradford 1976). $0.2 \mathrm{~g}$ of fresh leaf tissue was homogenized in phosphate buffer $(\mathrm{pH} 7.8,4 \mathrm{~mL})$ and centrifuged at $10,000 \times \mathrm{g}$. TAA content was quantified by using the following protocol (Hamilton et al. 1943). The quantification was done by treating the sample with $2 \%$ ninhydrin $(1 \mathrm{~mL})$ and $10 \%$ pyridine $(1 \mathrm{~mL})$. The absorbance was taken at $570 \mathrm{~nm}$ and leucine as used as a standard.

\section{Estimation of $\mathrm{Na}^{+}$and $\mathrm{K}^{+}$}

For the estimation of $\mathrm{Na}^{+}$and $\mathrm{K}^{+}$ions, dry sample (leaf and root, $0.1 \mathrm{~g}$ ) was digested in $2 \mathrm{~mL}$ of sulfuric- peroxide digestion mixture (Wang and Zhao 1995). Then deionized water was used to maintain the volume $(50 \mathrm{~mL})$ of each sample. The estimation of $\mathrm{Na}^{+}$and $\mathrm{K}^{+}$ion analysis was done by using a flame photometer.

\section{Gas exchange attributes}

For the measurement of leaf gas exchange attributes comprising, $A, E, A / E, g s$, and $C i$ using an open system Ci340 portable photosynthesis system (CID, USA). The measurements were made from 10:00 am to 14:00 pm with the subsequent amendments: leaf surface area $6.3 \mathrm{~cm}^{2}$, ambient CO 2 concentration $385 \mu \mathrm{mol} \mathrm{mol}^{-1}$, temperature of leaf chamber fluctuating from 40 to $43^{\circ} \mathrm{C}$, leaf chamber volume gas flow rate (v) $1068 \mathrm{~mL} \mathrm{~min}^{-1}$, leaf chamber molar gas flow rate (U) $1052 \mu \mathrm{mols}^{-1}$, ambient pressure (P) $100.09 \mathrm{kPa}$ and PAR (Q leaf) at leaf surface maximum up to $874 \mu \mathrm{mol} \mathrm{m} \mathrm{s}^{-2}$.

\section{Statistical analysis}

SPSS software package (SPSS In., USA.) and Excel (Microsoft, U.S.A.) was used to perform statistical analyses.
Duncan's multiple range tests were applied for the analysis of variance and LSD between means of data.

\section{Results}

\section{Chlorophyll constituents}

The quantum of chlorophyll constituents i-e., 'a', 'b', total chlorophyll and carotenoids contents were degraded significantly $(\mathrm{p}<0.001)$ with each increment of diesel oil stress in both verities viz., "MMRI Yellow" and "Pearl White" of maize crop (Table 1). However, the values of chlorophyll pigments were significantly increased in maize plants grown when the soil was inoculated with bacterial strains as compared to the non-inoculated growth medium. The contents of chl. 'a', 'b', total chlorophyll and carotenoids were increased by quantum of $32.3 \%, 59.8 \%$, $40.9 \%, 31.9 \%$, respectively in var. MMRI Yellow grown on inoculated growth medium over the non -inoculated soil condition. On the other hand, var. Pearl White grown on inoculated growth medium contained lower values of chl, a, $\mathrm{b}$, total chlorophyll, and carotenoids by an amount of $27.6 \% ; 56.5 \% ; 36.8 \%$; $9.8 \%$, respectively compared to noninoculated soil environment.

\section{Chlorophyll fluorescence attributes (Y (II), Fv/Fm, NPQ)}

The values of attribute Y(II) were reduced significantly $(\mathrm{P}<0.001)$ in crop plants on growth medium contaminated with $3.5 \mathrm{gkg}^{-1}$ diesel oil (Fig. 1A). However, the content of Fv/Fm was substantially increased in maize crop growing on inoculated soil medium (Fig. 1B). The var. MMRI Yellow maintained higher content of $\mathrm{Fv} / \mathrm{Fm}$ by $6.67 \%$ compared to Var. Pearl White, having an amount of $5.77 \%$ under inoculated growth medium as compared to noninoculated soil environment. Furthermore, the values of NPQ were enhanced significantly $(\mathrm{P}<0.001)$ by growing crop plants on growth medium inoculated with bacterial consortium. Under the inoculated growth medium, var. MMRI-Yellow contained lower value of NPQ by $2.92 \%$, contrarily to var. Pearl White having higher value of $4.2 \%$ as compared to non-inoculated growth condition (Fig 1C).

\section{Gas exchange attributes}

The data of the net $\mathrm{CO}_{2}$ assimilation rate $(A)$ was differed significantly $(\mathrm{P}<0.001)$ in response to various diesel regimes, inoculating growth medium with bacterial strains and crop varieties. The values of $A$ decreased substantially in crop plants with increasing levels of hydrocarbons. The crop treated with $3.5 \mathrm{~g} \mathrm{~kg}^{-1}$ diesel oil maintained minimal amount of net Photosynthetic rate (Fig. 2A). In concurrence with increasing levels of hydrocarbons, to the tune of $3.5 \mathrm{~g}$ $\mathrm{kg}^{-1}$ diesel oil, the transpiration rate $(E)$ was reduced to the where minimums levels (Fig. 2B). However, its values were appreciably enhanced in crop grown on bacterial consortium 
Table 1: Influence of varying diesel regimes on chlorophyll contents of Zea mays L. cultivated for 4 weeks with and without bioaugmentation of Pseudomonas aeruginosa BRRI54, Acinetobacter sp. BRSI56, Acinetobacter sp. ACRH80

\begin{tabular}{|c|c|c|c|c|c|c|}
\hline Varieties & Treatment & Hydrocarbon Concentration (g kg-1 soil) & Chlorophyll a & Chlorophyll b & Total Chlorophyll & Carotenoids \\
\hline \multirow[t]{8}{*}{ MMR1 yellow } & \multirow[t]{4}{*}{ Bacterial Consortium } & 0 & $0.51 \pm 0.00 \mathrm{a}$ & $0.28 \pm 0.00 \mathrm{a}$ & $0.80 \pm 0.01 \mathrm{a}$ & $0.37 \pm 0.00 \mathrm{a}$ \\
\hline & & 1.5 & $0.33 \pm 0.01 \mathrm{~b}$ & $0.17 \pm 0.02 b$ & $0.51 \pm 0.02 \mathrm{~b}$ & $0.25 \pm 0.01 \mathrm{~b}$ \\
\hline & & 2.5 & $0.31 \pm 0.00 \mathrm{c}$ & $0.15 \pm 0.01 b c$ & $0.46 \pm 0.01 \mathrm{~b}$ & $0.20 \pm 0.01 \mathrm{c}$ \\
\hline & & 3.5 & $0.28 \pm 0.00 \mathrm{c}$ & $0.11 \pm 0.01 \mathrm{c}$ & $0.40 \pm 0.01 \mathrm{c}$ & $0.18 \pm 0.01 \mathrm{c}$ \\
\hline & \multirow[t]{4}{*}{ Without Bacterial consortium } & 0 & $0.38 \pm 0.00 \mathrm{a}$ & $0.17 \pm 0.01 \mathrm{a}$ & $0.57 \pm 0.01 \mathrm{a}$ & $0.28 \pm 0.01 \mathrm{a}$ \\
\hline & & 1.5 & $0.31 \pm 0.00 \mathrm{~b}$ & $0.13 \pm 0.02 b$ & $0.43 \pm 0.00 \mathrm{~b}$ & $0.19 \pm 0.01 \mathrm{~b}$ \\
\hline & & 2.5 & $0.25 \pm 0.01 \mathrm{c}$ & $0.12 \pm 0.00 \mathrm{~b}$ & $0.38 \pm 0.03 b$ & $0.16 \pm 0.01 \mathrm{c}$ \\
\hline & & 3.5 & $0.17 \pm 0.00 \mathrm{~d}$ & $0.10 \pm 0.00 \mathrm{~b}$ & $0.28 \pm 0.00 \mathrm{c}$ & $0.14 \pm 0.01 \mathrm{c}$ \\
\hline \multirow[t]{8}{*}{ Pearl White } & \multirow[t]{4}{*}{ Bacterial Consortium } & 0 & $0.45 \pm 0.01 \mathrm{a}$ & $0.25 \pm 0.00 \mathrm{a}$ & $0.71 \pm 0.01 \mathrm{a}$ & $0.30 \pm 0.00 \mathrm{a}$ \\
\hline & & 1.5 & $0.32 \pm 0.00 \mathrm{~b}$ & $0.14 \pm 0.00 \mathrm{~b}$ & $0.46 \pm 0.01 \mathrm{~b}$ & $0.21 \pm 0.01 \mathrm{~b}$ \\
\hline & & 2.5 & $0.29 \pm 0.00 \mathrm{c}$ & $0.13 \pm 0.01 b$ & $0.43 \pm 0.01 \mathrm{c}$ & $0.19 \pm 0.01 b$ \\
\hline & & 3.5 & $0.27 \pm 0.00 \mathrm{~d}$ & $0.11 \pm 0.01 \mathrm{c}$ & $0.38 \pm 0.01 \mathrm{~d}$ & $0.16 \pm 0.01 \mathrm{c}$ \\
\hline & \multirow[t]{4}{*}{ Without Bacterial consortium } & 0 & $0.35 \pm 0.01 \mathrm{a}$ & $0.16 \pm 0.00 \mathrm{a}$ & $0.52 \pm 0.01 \mathrm{a}$ & $0.27 \pm 0.01 \mathrm{a}$ \\
\hline & & 1.5 & $0.28 \pm 0.00 \mathrm{~b}$ & $0.12 \pm 0.01 \mathrm{~b}$ & $0.40 \pm 0.01 \mathrm{~b}$ & $0.18 \pm 0.01 b$ \\
\hline & & 2.5 & $0.22 \pm 0.00 \mathrm{c}$ & $0.10 \pm 0.01 b c$ & $0.32 \pm 0.01 \mathrm{c}$ & $0.15 \pm 0.01 \mathrm{c}$ \\
\hline & & 3.5 & $0.15 \pm 0.00 \mathrm{~d}$ & $0.09 \pm 0.01 \mathrm{c}$ & $0.25 \pm 0.01 \mathrm{~d}$ & $0.14 \pm 0.01 \mathrm{c}$ \\
\hline
\end{tabular}

inoculated soil. The growth medium contaminated with diesel oil caused significant $(\mathrm{p}<0.001)$ reduction in wateruse-efficiency $(A / E)$. The greatest reduction of $A / E$ was recorded in crop grown on soil containing $1.5 \mathrm{~g} \mathrm{~kg}^{-1}$ diesel oil, while, its values were found to be improved by growing both crop varieties on soil contaminated with $3.5 \mathrm{~g} \mathrm{~kg}^{-1}$ diesel stress (Fig. 2C). The occurrence of have relative rate of Transpiration due to inoculation of growth medium with bacterial consortium resulted in changing stomatal conductance under diesel polluted stress environment. The values of stomatal conductance $(g s)$ and sub-stomatal $\mathrm{CO}_{2}$ (Ci) concentration were increased significantly in maize plants grown on growth medium inoculated with bacterial consortium as compared to non-inoculated growing conditions. However, values of these attributes were found in decreasing order with increasing concentration of diesel oil in growth medium (Fig 2D and E).

\section{Assimilation of Ionic Constituents by Leaves and Roots Tissue}

The application of diesel oil in root growing medium caused increase in assimilation of $\mathrm{Na}^{+}$ion by shoot and root organs of both maize varieties compared to non-hydrocarbon stress conditions. However, inoculation of growth medium with bacterial consortium cause substantial reduction in the uptake of $\mathrm{Na}^{+}$ion compared to non-inoculated growing condition. The maize varieties responded differently in the absorption of $\mathrm{Na}^{+}$growing under inoculated growing medium. In proportion to total amount of $\mathrm{Na}^{+}$, its absorption was decreased by var. MMRI Yellow and Pearl White to the tune of $13.08 \%$ and $11.31 \%$ respectively, in inoculated crop over the non-inoculated growth condition (Fig. 3C and D).

Successive increase in the levels of diesel stress caused sequential reduction in uptake of $\mathrm{K}^{+}$ion by shoot and root organs in both maize varieties. The uptake of $\mathrm{K}^{+}$ion was substantially improved by growing crop on growth medium inoculated with bacterial consortium. Var. "MMRI Yellow" assimilated higher amount of $\mathrm{K}^{+}$ion by $30.46 \%$ as compared to $29.73 \%$ by var. "Pearl White" once (Fig. $3 \mathrm{~A}$ and B).

\section{Total soluble protein and total free amino acid contents}

Addition of various concentration of diesel oil resulted in enhancement of total soluble proteins in root and shoot tissues of both varieties. The greater quantity of total soluble protein content were recorded in crop stressed at $3.5 \mathrm{~g} \mathrm{~kg}^{-1}$ as compared to non-polluted soil. Moreover, crop grown on soil enriched with bacterial consortium maintain higher amount total soluble protein in comparison with noninoculated growing environment (Fig. 4A, B). The values of total free amino acids were increased substantially in crop grown on diesel contaminated growth medium. Moreover, its value were also enhanced in root and shoot tissue of crop planted on soil inoculated with bacterial consortium. The maximum amount of total free amino acids were recorded in crop grown on soil contaminated with $3.5 \mathrm{~g} \mathrm{~kg}^{-1}$ as compared to other growth medium added with 1.5 and $2.5 \mathrm{~g}$ $\mathrm{kg}^{-1}$ diesel stress (Fig. 4C and D).

\section{Discussion}

The sustainability of chlorophyll constituents, gas exchange and pattern of uptake of ions were studied under hydrocarbon stress environment in maize crop. The findings of regarding physiological processes revealed that both maize varieties exhibited significantly greater production of quantum yield $(\mathrm{Fv} / \mathrm{Fm}$, photosystem II efficiency [Y(II)], high uptake of $\mathrm{K}^{+}$ions and $\mathrm{CO}_{2}$ assimilation rate, total free amino acid, and total soluble proteins; while lessening nonphotochemical quenching (NPQ), and transpiration rate, in response to inoculation of growth medium with bacterial strains. The plants growing on inoculated medium showed greater tolerance to hydrocarbon treated soil compared to un-inoculated environments.

The present investigation illustrated that inoculation of growth medium with bacterial strains produce beneficial 
effects in the environment of photosynthetic pigments, $\mathrm{Fv} / \mathrm{Fm}$ and photosystem II efficiency in plants under hydrocarbon stress. Ambreen et al. (2016) also reported same result in corn plant under crude oil stress. Another investigate supported our result by Agnello et al. (2016) in which Medicago sativa grown in diesel and heavy metal $(\mathrm{Cu}, \mathrm{Pb}$ and $\mathrm{Zn})$ contaminated soil and bioaugmentation with Pseudomonas aeruginosa showed better result of quantum yield of photosystem II ( $\mathrm{Fv} / \mathrm{Fm})$ in inoculated group as compare to non-inoculated group.

The chlorophyll synthesis was greater affected at a high concentration of hydrocarbon, while it was a little at the lower concentrations. The quantum of chl ' $a$ ' and chl ' $b$ ' content were not damaged to a greater proportion in maize plants in bacterial inoculated group. The degeneration of photosynthetic pigments might be affected due to membrane permeability and disturbance in the chloroplast. The results of our study showed that toxicity caused by hydrocarbon resulted in the diminishing of chloroplast function, which led to damage to the chlorophyll contents. However, these damaging effects were mitigated by inoculation with bacterial strains of hydrocarbon contaminated soil. The hydrocarbon stress caused significant damaging effect to the chlorophyll contents evidenced by Agnello et al. 2016 and Ambreen et al. 2016. However, Oryza sativa grown in phenanthrene and pyrene contaminated soil badly affects photosynthetic efficieny by causing disintegeration of chlorophyll contents but bacterial inoculation (Acinetobacteria sp.) mitigated effects of phenanthrene and pyrene in rice plant also reported by Li et al. 2008.

Results of our investigation showed that stomatal conductance and sub-stomatal $\mathrm{CO}_{2}$ concentration of both maize varieties were improved due to bacterial inoculation. Moreover, transpiration rate $(E)$ of both varieties were enhanced in inoculated group as compare to non-inoculated group. The leaves of hydrocarbon stressed maize varieties exhibited higher water use efficiency (WUE) as compare to control. Iwegbue et al. (2007) reported that the photosynthetic processes were inhibited, because of a reduction in net $\mathrm{CO}_{2}$ assimilation rate, transpiration rate, sub stomatal $\mathrm{CO}_{2}$ concentration and coupled with high ambient $\mathrm{CO}_{2}$ concentration. However, stomatal closure produces little effect on the process of photosynthesis. During the process, the light energy is captured by photosynthetic pigment to produce an excited state and contaminated stress was a marker to demonstrate a sign of plant photosynthetic efficiency (Qian et al. 2014). Whereas, other abiotic and biotic stresses also cause to reduce photosynthetic pigments and photosynthetic efficiency in plants (Wen et al. 2016; Li et al. 2018).

The results of our study documented carotenoids severely damaged by hydrocarbon stress in maize varieties grow in diesel contaminated soil. Ibemesim 2010 reported that sour grass grown in crude oil contaminated soil badly affects photosynthetic efficieny by causing disintegeration of chlorophyll contents.Carotenoids act as antioxidants as

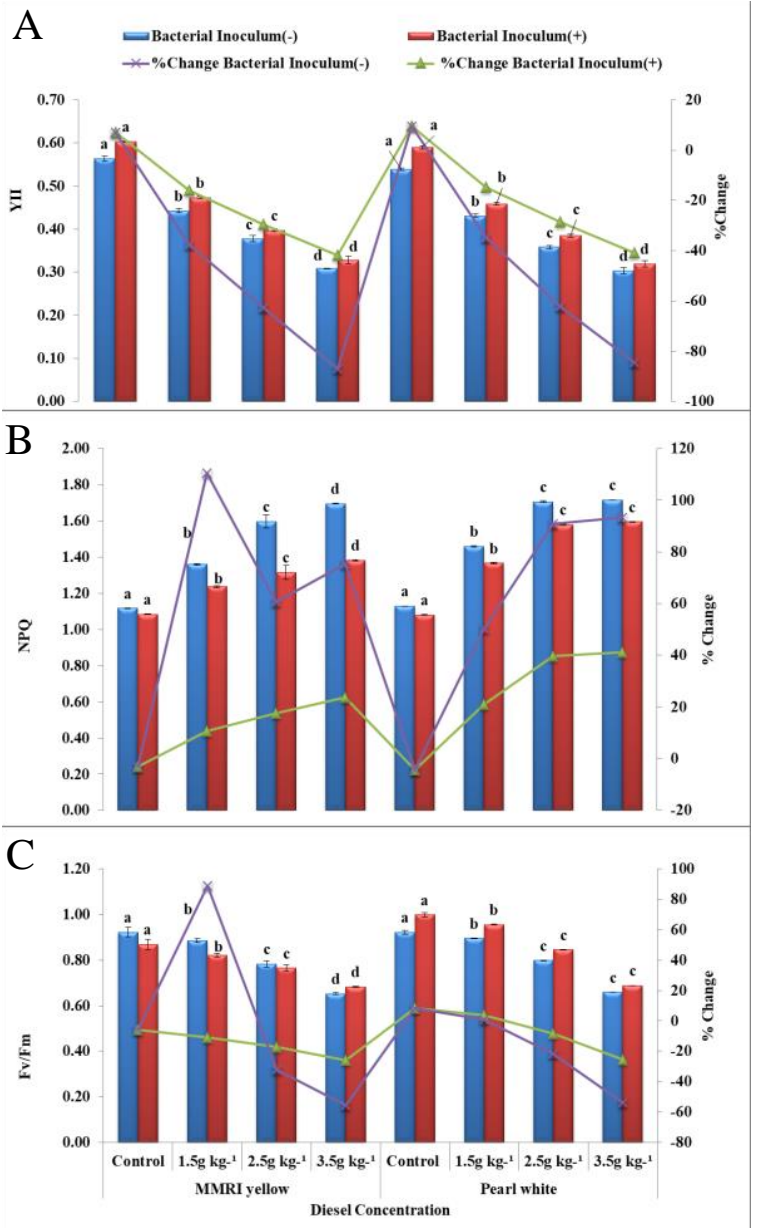

Fig. 1: Influence of varying diesel regimes on chlorophyll fluorescence attributes (Y (II), Fv/Fm, NPQ) of Zea mays L. Cultivated for 3 weeks with and without bioaugmentation of Pseudomonas aeruginosa BRRI54, Acinetobacter sp. BRSI56, Acinetobacter sp. ACRH80. (-) and (+) signs indicate that without inoculum and with inoculum

scavenge to free radicals, mitigating destruction of cells and avoiding damage to chlorophyll membrane when stressful conditions (Czerpak et al. 2006). Thereby, the quantum of chlorophyll content, biosynthesis of photosynthetic pigments, mineralization of mineral nutrients and essential metabolites were substantially affected by toxicity caused by hydrocarbons (Ibemesim 2010).

Our study showed that the inoculation of growth medium with bacterial strains resulted in reduced uptake of $\mathrm{Na}^{+}$ions by leaves and roots of maize plants. The reduction in absorption of $\mathrm{Na}^{+}$led to the improvement in plant growth and development by enhancing tolerance in the plant system. However, our investigation revealed that the uptake of $\mathrm{K}^{+}$ ion was also accelerated with simultaneously suppressing the uptake of $\mathrm{Na}^{+}$ion under inoculated conditions. The previous investigation by Ahmad et al. 2015 reported the similar results that bacterial inoculation (Trichoderma harzianum) alleviated the abiotic stress in Brassica junce. 


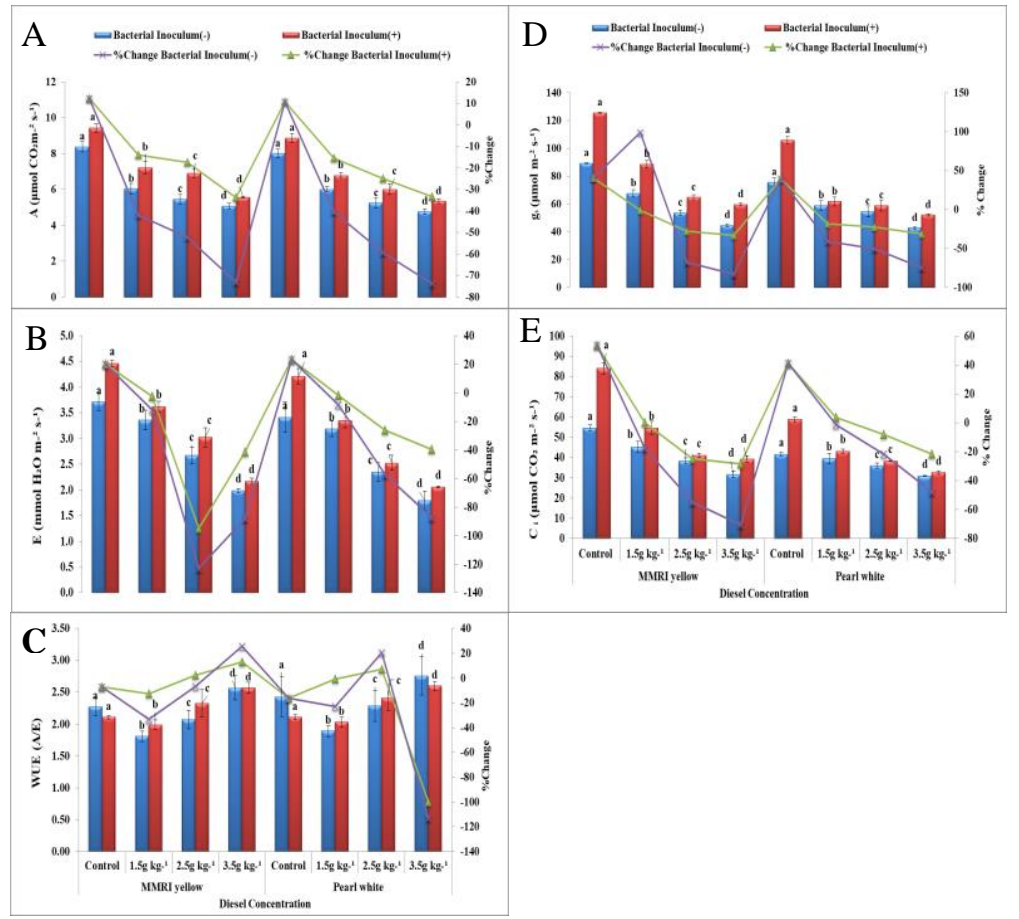

Fig. 2: Influence of varying diesel regimes on gas exchange attributes (A, B, C, D, E) of Zea mays L. cultivated for 6 weeks with and without bioaugmentation of Pseudomonas aeruginosa BRRI54, Acinetobacter sp. BRSI56, Acinetobacter sp. ACRH80. (-) and (+) signs indicate that without inoculum and with inoculum

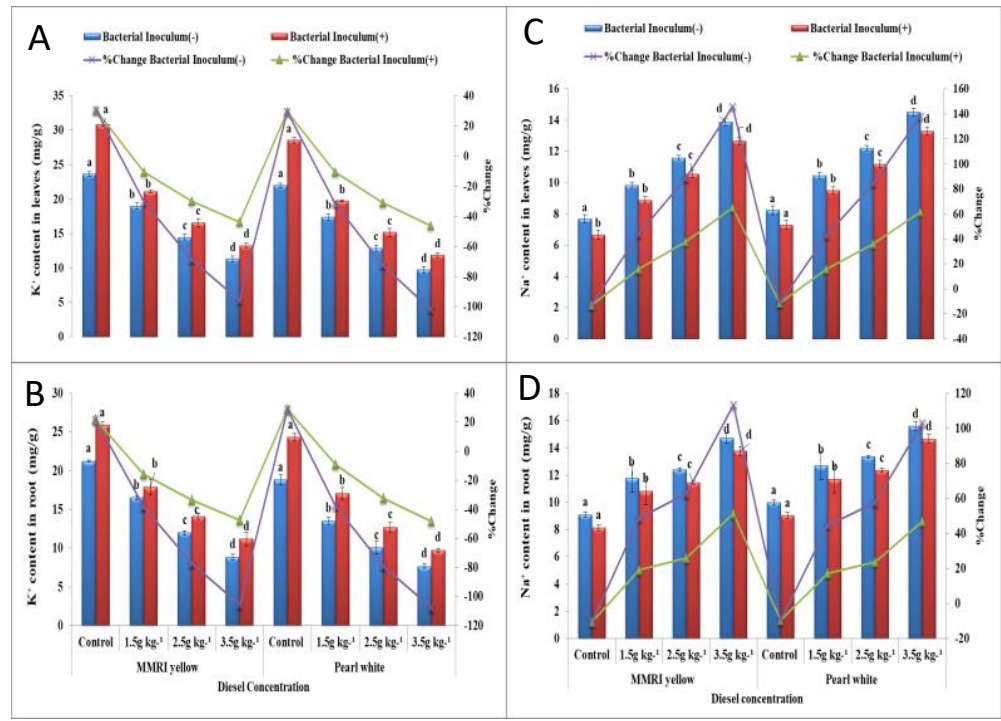

Fig. 3: Influence of varying diesel regimes on $\mathrm{K}^{+}(\mathrm{A}$ and $\mathrm{B})$ and $\mathrm{Na}^{+}(\mathrm{C}$ and $\mathrm{D})$ uptake in the leaf and root tissues of Zea mays $\mathrm{L}$. Cultivated for 6 weeks with and without bioaugmentation of Pseudomonas aeruginosa BRRI54, Acinetobacter sp. BRSI56, Acinetobacter sp. ACRH80. (-) and (+) signs indicate that without inoculum and with inoculum

Zhuang et al. (2007) revealed that inoculation of plant growth promoting bacteria enhanced the process mineralization and providing better condition for growth and development of the plant by reducing the effects of stressful environment. The inoculation of growth medium induces mineralization of minerals nutrients and creating a favourable environment for greater absorption of nutrients by plant roots (Meena et al. 2017).

The increased accumulation of total free soluble proteins and total free amino acids play a significant role in the maintenance of physiological functions in response to stressful conditions during the growth period 


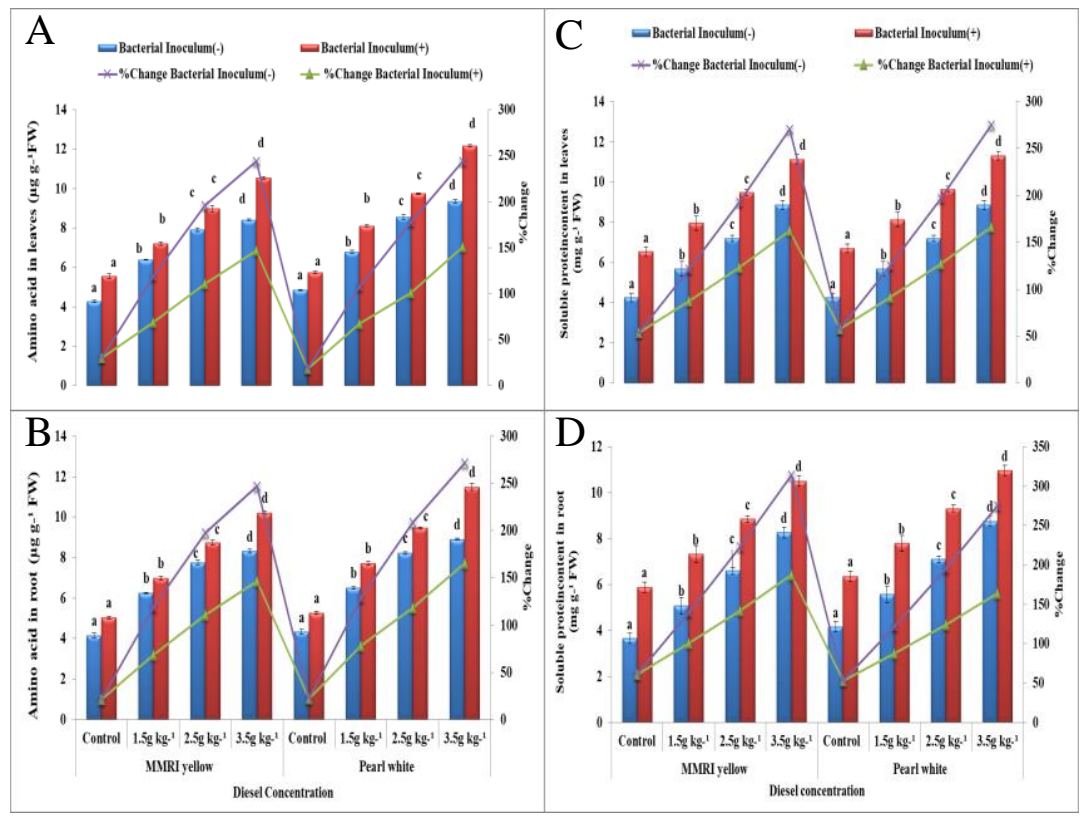

Fig. 4: Influence of varying diesel regimes on total free amino acids (A and B) and total soluble protein (C and D) of Zea mays L. cultivated for 4 weeks with and without bioaugmentation of Pseudomonas aeruginosa BRRI54, Acinetobacter sp. BRSI56, Acinetobacter sp. ACRH80. (-) and (+) signs indicate that without inoculum and with inoculum

(Ashraf and Harris 2004). The results of our study also revealed that quantum of total free amino acids and total soluble proteins also increased under stressful conditions of hydrocarbon present in the rhizosphere in maize crop. Ambreen et al. 2016 also reported that maize plant grown in crude oil contaminated soil showed increased amount of total soluble proteins and total free amino acid. Li et al. 2008 also reported that rice plant grown in polycyclic aromatic hydrocarbon contaminated soil showed enhanced leveel of total soluble proteins. The existence of a potential association between plants and microbes is important in degrading hydrocarbon substances from the soil (Afzal et al. 2012).

The bacterial degrade the complex structures of hydrocarbons and convert into soluble forms. Thereby, the nutrients are made available and easily absorbed by plant roots, restoring to improving tolerance to stress conditions (Muratova et al. 2012; Hou et al. 2015; Gerhardt et al. 2017a; Gerhardt et al. 2017b).

Moreover, vegetation covers also provide the habit for microbes to burgeon their population in the vicinity of roots in the rhizosphere (Susarla et al. 2002). The microbial populations in the rhizosphere do not only degrade substances of hydrocarbons but also convert other crop residues and farmyard manure into soluble substance. The products work as biofertilizers, psychostimulants and creating a favorable environment for better growth and development. The prevalence of a better rhizosphere microenvironment for plant roots resort to a greater proliferation of microbial activities (Braud et al. 2009; Hayat et al. 2010).

\section{Conclusion}

A pot-culture study was undertaken to quantify the association of bacterial consortium to degrade the diesel polluted soil. The cereal maize (Zea mays L.) crop was used as test plant. The findings of this research indicated that contamination of soil with PAHs impacted negatively on the growth and development of maize crop. The maximum concentration of $3.5 \mathrm{~g} \mathrm{~kg}^{-1}$ diesel oil proved to be more injurious on various physiological and biochemical attributes. The negative effects of polluted soil could be ameliorated by inoculation of growth medium with bacterial consortium, viz. Pseudomonas aeruginosa BRRI54, Acinetobacter sp. ACRH80 and Acinetobacter sp. BRSI56. The soil inoculated with bacterial strains caused improvement in photosynthetic machinery, assimilation of $\mathrm{K}^{+}$at the cost of $\mathrm{Na}^{+}$ion by plant organs and osmotic adjustment via accumulation of total proteins and amino acids.

The preliminary experimental evidence has shown that inoculation of soil with various bacterial strains that hold good in the different eco-edaphic environment could be best utilized to bring back hydrocarbon polluted soil under plough for development agro-forestry sector. The small farming households would be greatly benefited to bring their marginal lands for cultivation of maize crop. The bacterial strains employed in this study were isolated from the natural habitat. Therefore, these strains would have an equal opportunity to survive in different farming system. The finding of this study could be extrapolated under field condition. Moreover, the research and endeavors could be 
strengthen to isolate more environment friendly bacterial strains, that could be more efficient and greater capability to survive for degradation of diesel polluted soil.

\section{Authors Contributions}

UU, SN, ZUZ and MA designed the experimental setup and UU conducted the experiments. UU and SN wrote the manuscript. UU analyzed the data. SN critically revised the manuscript to the current form.

\section{References}

Afzal M, QM Khan, A Sessitsch (2014). Endophytic bacteria: Prospects and applications for the phytoremediation of organic pollutants. Chemosphere 117:232-242

Afzal M, S Khan, S Iqbal, MS Mirza, QM Khan (2013). Inoculation method affects colonization and activity of Burkholderia phytofirmans PsJN during phytoremediation of diesel-contaminated soil. Intl Biodeterior Biodegrad 85:331-336

Afzal M, S Yousaf, TG Reichenauer, A Sessitsch (2012). The inoculation method affects colonization and performance of bacterial inoculant strains in the phytoremediation of soil contaminated with diesel oil Intl J Phytoremediation 14:35-47

Agnello AC, M Bagard, ED Van Hullebusch, G Esposito, D Huguenot (2016). Comparative bioremediation of heavy metals and petroleum hydrocarbons co-contaminated soil by natural attenuation, phytoremediation, bioaugmentation and bioaugmentation-assisted phytoremediation. Sci Total Environ 563:693-703

Ahmad P, A Hashem, EF Abd-Allah, A Alqarawi, R John, D Egamberdieva, $S$ Gucel (2015). Role of Trichoderma harzianum in mitigating $\mathrm{NaCl}$ stress in Indian mustard (Brassica juncea L) through antioxidative defense system. Frontiers Plant Sci 6:868

Aisien F, J Chiadikobi, E Aisien (2009). Toxicity assessment of some crude oil contaminated soils in the Niger delta: Advanced materials research, Trans Tech Publ Switzerl 62:451-455

Alam M (2008). Parco, SSGC cagey about Korangi oil spill. published in "The Daily Dawn" December

Almaghrabi OA, SI Massoud, TS Abdelmoneim (2013). Influence of inoculation with plant growth promoting rhizobacteria (PGPR) on tomato plant growth and nematode reproduction under greenhouse conditions. Saudi J Biol Sci 20:57-61

Ambreen S, M Javed, M Hina, S Rasul, ZU Zafar, H Manzoor, CC Ogbaga, M Afzal, F Al-Qurainy, M Ashraf (2016). Influence of sub-lethal crude oil concentration on growth, water relations and photosynthetic capacity of maize (Zea mays L.) plants. Environmental Sci Pollut Res 23:18320-18331

Aronoff S (1946). Photochemical reduction of chloroplast grana. Plant Physiol 21:393

Ashraf M, P Harris (2004). Potential biochemical indicators of salinity tolerance in plants. Plant Sci 166:3-16

Baldan E, M Basaglia, F Fontana, JP Shapleigh, S Casella (2015). Development, assessment and evaluation of a biopile for hydrocarbons soil remediation. Intl Biodeterior Biodegrad 98:66-72

Bradford MM (1976). A rapid and sensitive method for the quantitation of microgram quantities of protein utilizing the principle of protein-dye binding. Anal Biochem 72:248-254

Braud A, K Jézéquel, S Bazot, T Lebeau (2009). Enhanced phytoextraction of an agricultural $\mathrm{Cr}$-and $\mathrm{Pb}$-contaminated soil by bioaugmentation with siderophore-producing bacteria. Chemosphere 74:280-286

Chang P, KE Gerhardt, XD Huang, XM Yu, BR Glick, PD Gerwing, BM Greenberg (2014). Plant growth-promoting bacteria facilitate the growth of barley and oats in salt-impacted soil: Implications for phytoremediation of saline soils. Intl J Phytoremediation 16:11331147

Cachada A, T Rocha-Santos, AC Duarte (2018). Soil and pollution: an introduction to the main issues Soil pollution, pp:1-28. Elsevier, Amsterdam, The Netherlands
Czerpak R, A Piotrowska, K Szulecka (2006). Jasmonic acid affects changes in the growth and some components content in alga Chlorella vulgaris. Acta Physiol Plant 28:195-203

Dixit A, M Nigam, R Mishra (2016). A development of a decision support system for remediation option selection for contaminated sites. $A d v$ Eng Appl Sci: Intl J 6:34-45

Fatima K, M Afzal, A Imran, QM Khan (2015). Bacterial rhizosphere and endosphere populations associated with grasses and trees to be used for phytoremediation of crude oil contaminated soil. Bull Environ Contam Toxicol 94:314-320

Fatima K, A Imran, I Amin, Q Khan, M Afzal (2016). Plant species affect colonization patterns and metabolic activity of associated endophytes during phytoremediation of crude oil-contaminated soil. Environmental Sci Pollut Res 23:6188-6196

Gerhardt KE, PD Gerwing, BM Greenberg (2017a). Opinion: Taking phytoremediation from proven technology to accepted practice. Plant Sci 256:170-185

Gerhardt KE, GJ MacNeill, PD Gerwing, BM Greenberg (2017b). Phytoremediation of salt-impacted soils and use of plant growthpromoting rhizobacteria (PGPR) to enhance phytoremediation Phytoremediation, pp: 19-51. Springer

Guo M, Z Gong, R Miao, D Su, X Li, C Jia, J Zhuang (2017). The influence of root exudates of maize and soybean on polycyclic aromatic hydrocarbons degradation and soil bacterial community structure. Ecol Eng 99:22-30

Hamilton PB, DD Van Slyke, S Lemish (1943). The gasometric determination of free amino acids in blood filtrates by the ninhydrincarbon dioxide method. J Biol Chem 150:231-250

Hayat R, S Ali, U Amara, R Khalid, I Ahmed (2010). Soil beneficial bacteria and their role in plant growth promotion: a review. Annal Microbiol 60:579-598

Hentati O, R Lachhab, M Ayadi, M Ksibi (2013). Toxicity assessment for petroleum-contaminated soil using terrestrial invertebrates and plant bioassays. Environ Monit Assess 185:2989-2998

Hou J, W Liu, B Wang, Q Wang, Y Luo, AE Franks (2015). PGPR enhanced phytoremediation of petroleum contaminated soil and rhizosphere microbial community response. Chemosphere 138:592598

Ibemesim R (2010). Effect of salinity and Wytch farm crude oil on Paspalum conjugatum Bergius (sour grass). J Biol Sci 10:122-130

Iwegbue C, F Emuh, N Isirimah, A Egun (2007). Fractionation, characterization and speciation of heavy metals in composts and compost-amended soils. Afr J Biotechnol 6:67-78

Jabeen H, S Iqbal, F Ahmad, M Afzal, S Firdous (2016). Enhanced remediation of chlorpyrifos by ryegrass (Lolium multiflorum) and a chlorpyrifos degrading bacterial endophyte Mezorhizobium sp. HN3. Intl J Phytoremediation 18:126-133

Kaimi E, T Mukaidani, S Miyoshi, M Tamaki (2006). Ryegrass enhancement of biodegradation in diesel-contaminated soil. Environ Exp Bot 55:110-119

Khan K (2009). Train accident suspends railway traffic in Sindh. Published in "The Daily Dawn" September, 2009

Khan Z, D Roman, T Kintz, M delas Alas, R Yap, S Doty (2014). Degradation, phytoprotection and phytoremediation of phenanthrene by endophyte Pseudomonas putida, PD1. Environ Sci Technol 48:12221-12228

Li J, Y Gao, S Wu, K Cheung, X Wang, M Wong (2008). Physiological and biochemical responses of rice (Oryza sativa L.) to phenanthrene and pyrene. Intl J Phytoremediation 10:106-118

Li L, X Chen, D Zhang, X Pan (2010). Effects of insecticide acetamiprid on photosystem II (PSII) activity of Synechocystis sp. (FACHB-898). Pestic Biochem Physiol 98:300-304

Li X, M Ke, M Zhang, W Peijnenburg, X Fan, J Xu, Z Zhang, T Lu, Z Fu, $\mathrm{H}$ Qian (2018). The interactive effects of diclofop-methyl and silver nanoparticles on Arabidopsis thaliana: Growth, photosynthesis and antioxidant system. Environ Pollut 232:212-219

Mair J, F Schinner, R Margesin (2013). A feasibility study on the bioremediation of hydrocarbon-contaminated soil from an alpine former military site: Effects of temperature and biostimulation. Cold Regions Sci Technol 96:122-128 
Meena KK, AM Sorty, UM Bitla, K Choudhary, P Gupta, A Pareek, DP Singh, R Prabha, PK Sahu, VK Gupta (2017). Abiotic stress responses and microbe-mediated mitigation in plants: The omics strategies. Front Plant Sci 8; Article 172

Muratova AY, SN Golubev, EV Dubrovskaya, NN Pozdnyakova, LV Panchenko, EV Pleshakova, MP Chernyshova, OV Turkovskaya (2012). Remediating abilities of different plant species grown in diesel-fuel-contaminated leached chernozem. Appl Soil Ecol 56:51-57

National Environmental Policy of Pakistan (1999). Pakistan Environmental Protection Agency; State of Environment Report, p:42

Naveed M, B Mitter, TG Reichenauer, K Wieczorek, A Sessitsch (2014). Increased drought stress resilience of maize through endophytic colonization by Burkholderia phytofirmans PsJN and Enterobacter sp. FD17. Environ Exp Bot 97:30-39

Njoku K, M Akinola, B Oboh (2009). Phytoremediation of crude oil contaminated soil: The effect of growth of Glycine max on the physico-chemistry and crude oil contents of soil. Nat Sci 7:79-87

Palaniyandi S, K Damodharan, S Yang, J Suh (2014). Streptomyces sp. strain PGPA39 alleviates salt stress and promotes growth of 'Micro Tom'tomato plants. J Appl Microbiol 117:766-773

Peng S, Q Zhou, Z Cai, Z Zhang (2009). Phytoremediation of petroleum contaminated soils by Mirabilis Jalapa L. in a greenhouse plot experiment. J Hazard Mater 168:1490-1496

Pilon-Smits E (2005). Phytoremediation. Annu Rev Plant Biol 56:15-39

Qian H, X Peng, X Han, J Ren, K Zhan, M Zhu (2014). The stress factor, exogenous ascorbic acid, affects plant growth and the antioxidant system in Arabidopsis thaliana. Russ J Plant Physiol 61:467-475

Ramadass K, M Megharaj, K Venkateswarlu, R Naidu (2015). Ecological implications of motor oil pollution: Earthworm survival and soil health. Soil Biol Biochem 85:72-81

Rodríguez-Eugenio N, M McLaughlin, D Pennock (2018). Soil pollution, $a$ hidden reality: What is soil pollution?, pp:1-41. FAO

Sessitsch A, M Kuffner, P Kidd, J Vangronsveld, WW Wenzel, K Fallmann, M Puschenreiter (2013). The role of plant-associated bacteria in the mobilization and phytoextraction of trace elements in contaminated soils. Soil Biol Biochem 60:182-194
Shahzad A, S Saddiqui, A Bano (2016). The response of maize (Zea mays L.) plant assisted with bacterial consortium and fertilizer under oily sludge. Intl J Phytoremediation 18:521-526

Souza EC, TC Vessoni-Penna, RP de Souza Oliveira (2014). Biosurfactantenhanced hydrocarbon bioremediation: An overview. Intl Biodeterior Biodegrad 89:88-94

Susarla S, VF Medina, SC McCutcheon (2002). Phytoremediation: An ecological solution to organic chemical contamination. Ecol Eng 18:647-658

Ummara U, S Noreen, M Afzal, P Ahmad (2020). Bacterial bioaugmentation enhances hydrocarbon degradation, plant colonization and gene expression in diesel-contaminated soil. Physiol Plantarum. In press

Wang BS, KF Zhao (1995). Comparison of extractive methods of Na and K in wheat leaves. Plant Physiol Commun 31:50-51

Wang S, D Zhang, X Pan (2012). Effects of arsenic on growth and photosystem II (PSII) activity of Microcystis aeruginosa. Ecotoxicol Environ Saf 84:104-111

Wen Y, L Zhang, Z Chen, X Sheng, J Qiu, D Xu (2016). Co-exposure of silver nanoparticles and chiral herbicide imazethapyr to Arabidopsis thaliana: Enantioselective effects. Chemosphere $145: 207-214$

Xun F, B Xie, S Liu, C Guo (2015). Effect of plant growth-promoting bacteria (PGPR) and arbuscular mycorrhizal fungi (AMF) inoculation on oats in saline-alkali soil contaminated by petroleum to enhance phytoremediation. Environ Sci Pollution Res 22:598-608

Yousaf S, K Ripka, T Reichenauer, V Andria, M Afzal, A Sessitsch (2010). Hydrocarbon degradation and plant colonization by selected bacterial strains isolated from Italian ryegrass and birdsfoot trefoil. $J$ Appl Microbiol 109:1389-1401

Zhang H, J Tang, L Wang, J Liu, RG Gurav, K Sun (2016). A novel bioremediation strategy for petroleum hydrocarbon pollutants using salt tolerant Corynebacterium variabile HRJ4 and biochar. J Environ Sci 47:7-13

Zhuang X, J Chen, H Shim, Z Bai (2007). New advances in plant growth promoting rhizobacteria for bioremediation. Environ Int 33 406-413 